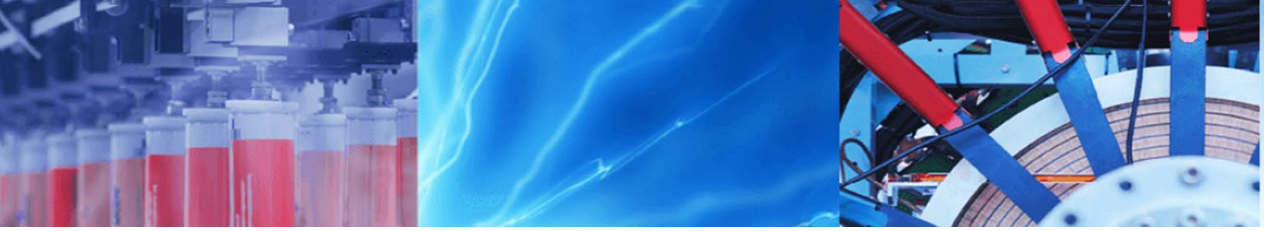

Research Article

\title{
Numerical analysis of bearing capacity of multiple strip footing on unreinforced and reinforced sand beds
}

\author{
Ahmed Fathy Zidan ${ }^{1}\left[\right.$ Mostafa Mohamed ${ }^{2}$
}

Received: 9 August 2019 / Accepted: 17 October 2019 / Published online: 26 October 2019

(c) Springer Nature Switzerland AG 2019

\begin{abstract}
In this paper, the ultimate bearing capacity of multiple strip footings on reinforced and unreinforced sand beds is investigated using finite element method. The study utilizes efficiency factor to assess the change in the ultimate bearing capacity due to footing interference. The impacts of angle of internal friction, clear footing spacing and number of reinforcement layers on the efficiency factor are presented and evaluated. In addition, the effect of dilatancy angle and stress distribution in soil-reinforcement system is examined. The developed numerical model was verified against available theoretical and experimental data from literature prior to its use in this study. It is noted that for both reinforced and unreinforced sand, the ultimate bearing capacity of strip footings in a group is always greater than that of a single footing when the footing spacing is less than twice the footing width. Furthermore, the efficiency factor was found to increase as the footing spacing decreased and as the number of reinforcement layers increased. The degree of enhancement in ultimate capacity is, therefore, dependent on the angle of internal friction and number of reinforcement layers. The paper also proposes and assesses the use of alternative approach to modelling the effect of reinforcement using an apparent cohesion to reflect the addition of reinforcement layer. The use of apparent cohesion seems reasonable but further investigations would be required.
\end{abstract}

Keywords Geosynthetics · Soil reinforcement · Bearing capacity · Finite element analysis · Soil dilatancy · Apparent cohesion

\section{Introduction}

The bearing capacity of soils has extensively been investigated for a long time [1-8]. The existence of a single footing in a semi-infinite half-space is unrealistic due to the complex nature and the wide variety of engineering structures for which footings might be constructed in groups of multiple configurations in large buildings or as a series of parallel sleepers (footings) in the railway. According to Terzaghi's theory concerning the failure mechanism of footings, the lateral distance of passive zones extends from three to five times the footing width based on the internal friction angle of the foundation soil. Therefore, if an adjacent footing is constructed within this distance, interaction between the two footings takes place affecting the bearing capacity of soil. Another fundamental difference is that an asymmetrical failure occurs underneath the two neighboring footings due to the imbalanced forces. Whereas in the case of a group of multiple footings or a series of footings, a symmetrical failure in the soils must occur. As a result, substantial influence occurs on the bearing capacity behavior. Thus, it is imperative that better understanding is developed for the effect of interaction of multiple footings in a series.

\footnotetext{
$\triangle$ Ahmed Fathy Zidan, ahmedzidan@eng.bsu.edu.eg; Mostafa Mohamed, M.H.A.Mohamed@Bradford.ac.uk|'Department of Civil Engineering, Faculty of Engineering, Beni-Suef University, Salah Salem Street, Beni Suef 62511, Egypt. ${ }^{2}$ Faculty of Engineering and Informatics, University of Bradford, Bradford, West Yorkshire BD7 1DP, UK.
} 
A number of studies were conducted to compute the ultimate bearing capacity of a group of footings and it is understood from these studies that the ultimate bearing capacity of multiple footings in a group is always greater than that of a single footing. This is due to the interaction between multiple footings. This interaction caused an increase in the confining pressure around the failure zones leading to increase shear resistance and bearing capacity.

Some of these investigations were performed on two adjacent strip footings on unreinforced sand beds [9-12]. Investigations to assess the bearing capacity of multiple footings in a series that are in close proximity are limited [13-16].

In recent decades, reinforced soils are frequently used to support footings in order to increase the footing bearing capacity and reduce potential settlement. Several experimental, analytical and numerical investigations have been performed to determine the response of footings rested on reinforced soils [17-31]. The effect of interaction between two neighboring foundations above reinforced soil on the ultimate bearing capacity has received increasing attention [26, 31-35]. Ghazavi and Lavasan [33] employed the definition of interference factor (If) which was defined as the ratio of ultimate bearing capacity of interfering footings on reinforced sand to that of a single footing resting on unreinforced sand to describe the beneficial effect of interaction of two closely spaced footings on the reinforced sand. The influence of geometry and orientation of geogrid layers on footings performance was also studied. In their study, the reinforcement under two shallow footings caused bearing capacity to increase by 150 and $200 \%$ after the addition of one and two reinforcement layers respectively. Lavasan and Ghazavi [26] evaluated the effect of interference on the behavior of closely spaced two square and circular footings on reinforced sand beds. It was found that tilting of footings was significantly influenced by the number of reinforced layers. Based on laboratory experiments on reinforced sand overlying soft clay, Roy and Deb [35] suggested that the interference factor is a function of the dimensions of the rectangular footings. It should be noted that the above studies were conducted on two closely spaced footings. Due to the scare of data for all variable parameters, the influence of various influential parameters e.g. type of soil, degree of soil packing and number of reinforcement layers on the behavior of multiple footings in a series that are in close proximity needs to be assessed.

In this paper, the performance of both single and multiple strip footings in a series resting on reinforced and unreinforced sand is studied. A series of Finite Element (FE) analyses was performed to evaluate the influence of (1) clear spacing between footings, (2) angle of internal friction, (3) angle of dilation and (4) number of reinforcement layers on the ultimate bearing capacity. In order to verify the FE model utilized in this study, the results of preliminary investigations are compared with those attained based on theoretical and experimental investigations which are available in the technical literature. The results are presented in a dimensionless form as illustrated thereafter. Additionally, the effect of dilation angle on the ultimate bearing capacity and the changing of stress distribution in vertical and horizontal direction due to reinforcement existing is also presented in this study. Furthermore, the achieved data for footing-reinforcement systems are used to assess an equivalent approach which relies on assuming an apparent cohesion value for the reinforced soil zone. The proposed approach simplifies the FE solution since the requirement to model the interaction between reinforcement and surrounding soils is no longer needed.

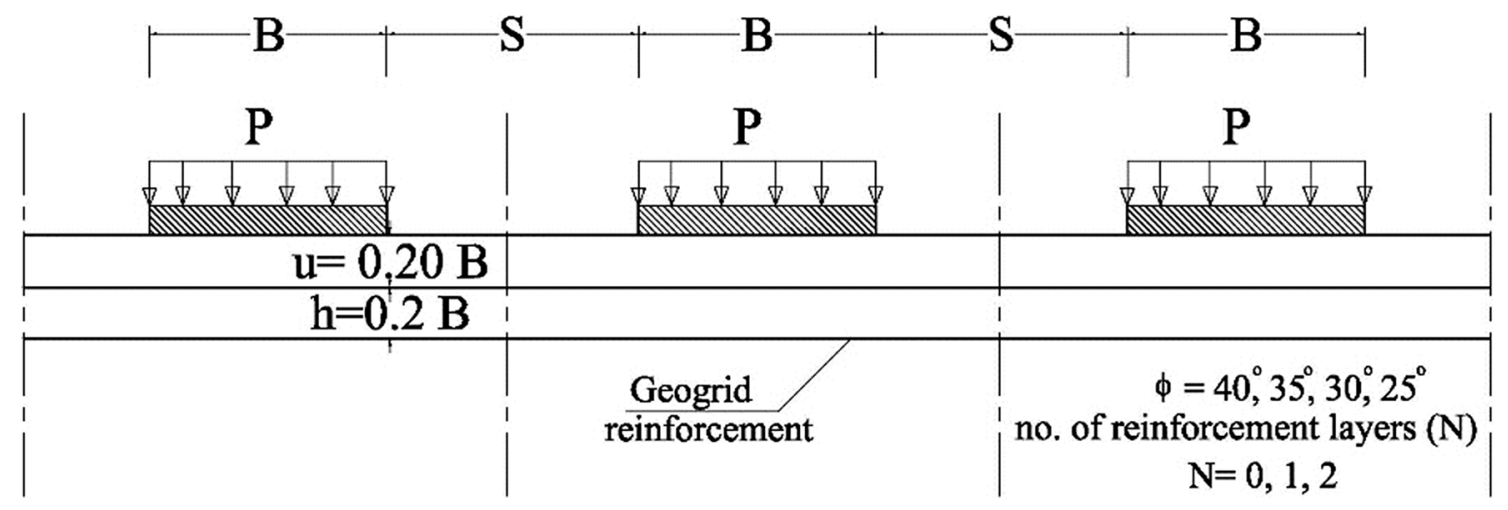

Fig. 1 Multiple strip footings: case identification and parameters 


\section{Problem definition and numerical model}

Figure 1 shows a schematic representation of the problem geometry for a multiple rigid strip footings with width B on cohesionless soil with a specific unit weight $(\gamma)$. It shows that the footings are equally loaded $(P)$ and constructed at the same clear space (S). The finite element simulations compute the ultimate load $\left(P_{\mathrm{u}}\right)$ of all the footings when they are loaded simultaneously to failure. The ultimate bearing load is determined as a function of the angle of internal friction $(\phi)$ and the spacing between footing on both reinforced and unreinforced sand. Furthermore, this study assumes an infinite number of footings collapse at the same ultimate load. In order to normalize the results, the performance of a footing in a group of footings is compared to that of a single footing for both reinforced and unreinforced sand scenarios.

The numerical investigation in this study is based on two-dimensional finite element modelling using Plaxis2D V8.2 [36]. Because this study sought the failure load of footing irrespective of its settlement, Mohr-Coulomb failure criterion with friction angle $\phi$ is assumed to be applicable for soil modeling. The soil is modelled as 15-noded triangular plane strain elements. Although, Plaxis enables the automatic mesh generation, the mesh size was refined in the area beneath the footing and around the reinforcement layers to enhance the accuracy of the simulations. The selection of the element size is a key factor in such study. Therefore, different finite element meshes were examined to reduce the mesh effects on the finite element results particularly due to changing the number of reinforcement layers and the model size. Due to the geometry of the group of footings in a series as presented in Fig. 1, the stresses and strains must be symmetrical around the vertical axes that pass through the center of footings $(\mathrm{B} / 2)$ and the middle distance between footings $(\mathrm{S} / 2)$. Consequently, the rectangular domain bounded by those two axes of symmetry is modelled to perform the analysis of a group of footings in a series.

The depth of soil in the numerical model is kept constant at $10 \mathrm{~B}$ as the collapse load remained unchanged irrespective of the increasing soil depth beyond this value. The vertical boundaries of model are restrained horizontally while the bottom boundary is constrained in both horizontal and vertical directions. On the other hand, full model is developed to model the single footing resting on unreinforced and reinforced sand with the same layer spacing shown in Fig. 1.

In this paper, the ultimate bearing capacity is sought irrespective of footing settlement therefore, the effect of soil modulus $(E)$ in predicting the interaction behavior has not been dealt with in this study [16], Different values for the angle of internal friction of sand of $\phi=25^{\circ}$, $30^{\circ}, 35^{\circ}, 40^{\circ}$ are studied to determine its effect on the system performance. The value of Poisson's ratio of 0.3 is kept constant through the analyses. Load control method is used accompanied with iterative analysis up to failure using internal friction angle as a failure criteria [37]. The dilation angle $(\psi)$ is also taken into consideration. Therefore, in all analyses, Rowe's stress-dilatancy relationship was used in order to determine the angle of dilation as follow [38, 39]:

$\psi=1.25\left(\phi-\phi_{\text {cri }}\right)$

where $\phi$ and $\phi_{c r i}$ are the angle of friction and the critical friction angle respectively. The critical friction angle for quartz sand ranges from about $28^{\circ}$ to $36^{\circ}$ depending on several parameters such as uniformity and shape of particles and mineralogy. Generally, the friction angle at the critical state is assumed to be constant and independent of density. For granular materials, the recommended value of critical friction angle is about $30^{\circ}$ [40].

For reinforced sand, the performance of footings is investigated with one and two reinforcement layers $(\mathrm{N}=1,2)$. A stiffness $(\mathrm{k})$ of $100 \mathrm{kN} / \mathrm{m}^{\prime}$ is assumed to be maintained in the current study for all reinforcement material. The interaction between soil and reinforcement layers is modelled by means of interface elements at the both sides of each layer. The effect of interface reduction factor (reduction of friction compared to the soil friction angle) is presented hereinafter. For the case of a single footing on reinforced sand, the width of reinforcement is taken as $7 \mathrm{~B}$ for all analyses.

In the finite element analyses, the footing is modelled by rigid plate element. The plate is homogenous, isotropic and the normal and flexural stiffness of footing are kept constant in all analyses and the pressure is applied on the top of the footing.

The number of elements and mesh size are maintained fixed through the analyses of model which have the same geometrical dimensions and soil properties. The reinforcement layers are modelled. However, they can be activated or deactivated to simulate the existing of reinforcement layers and unreinforced bed cases respectively. Of note, prior to the application of footing load, the initial conditions including the initial geometry configurations and initial effective stresses were established. The initial effective stresses are generated by means of $\mathrm{k}_{0}$ procedure.

The ultimate bearing capacity for a strip footing is generally computed by Terzaghi's equation which combines the effect of cohesion (c), surcharge (q) and soil unit weight $(\gamma)$. The equation is typically written as follow:

$\mathrm{q}_{\mathrm{u}}=\mathrm{cN}_{\mathrm{c}}+\mathrm{qN}_{\mathrm{q}}+0.5 \gamma \mathrm{BN}_{\gamma}$ 
The present study, for a single footing, deals with the determination of ultimate bearing capacity in the form of $\mathrm{N}_{\gamma}$. Therefore, in order to isolate the contribution of the soil unit weight factor $\mathrm{N}_{\gamma^{\prime}}$ the effects of other terms $\mathrm{N}_{\mathrm{c}}$ and $\mathrm{N}_{\mathrm{q}}$ are eliminated by assuming the soil is cohesionless and the footings are to be constructed at ground surface i.e. without surcharge (q).

\section{Verification of numerical model}

In order to verify the developed numerical model in this study, data from previous numerical and experimental studies that are available in the technical literatures were used. The verification phase included comparison of results under different conditions. The proposed model was first validated using data for the bearing capacity of a single footing on unreinforced sand. The present results were compared with those obtained using the lower bound finite element limit analysis solution reported by Kumar and Bhattacharya [16]; Kumar and Khatri [6]; Ukritchon et al. [4]; and Hijaj et al. [5]. Furthermore, it was also compared with the method of characteristic solution obtained by Kumar [7]. Concerning to the case of multiple footings on unreinforced sand, results of the numerical model were verified using the results of Kumar and Bhattacharya [16]. On the other hand, for a single footing on reinforced sand, the validity of the current study was conducted using the experimental results of Das et al. [20]. Moreover, the numerical model is examined and compared by the results reported by Ghosh's [41] which computed the response of two closely footings on reinforced sand. Hereafter results of the verification are presented and discussed prior to conduction of the comprehensive parametric study.

\subsection{Single footing on unreinforced sand}

Table 1 illustrates the values of $\mathrm{N}_{\gamma}$ for a single footing on unreinforced sand for different values of friction angle $\left(5^{\circ}\right.$, $10^{\circ}, 15^{\circ}, 20^{\circ}, 25^{\circ}, 30^{\circ}, 35^{\circ}, 40^{\circ}$ ) where;

$\mathrm{N}_{\gamma}=\frac{q_{u}}{0.5 \gamma B}$.

As presented in Table 1, except for $\phi<15^{\circ}$, the values of $\mathrm{N}_{\gamma}$ predicted from the current analysis matched quite well with reported results.

\subsection{Multiple strip footings on unreinforced sand}

Kumar and Bhattacharya [16] determined ultimate bearing capacity of multiple strip footings resting on unreinforced sand. All footings were identically spaced with clear distance (S) and equally loaded to failure load. Their study was based on the finite element with lower bound limit analysis and results were presented in terms of an efficiency factor $(\xi)$; where $\xi$ is the ratio of ultimate load carried by a single strip footing in a group to the ultimate load of isolated strip footing at the same conditions. The current numerical procedure is functioned to solve the same problem of Kumar and Bhattacharya [16]. Figure 2 shows the comparison between the magnitude of (६) conducted by their experimental study and present numerical analysis. The efficiency factor is determined with respect to changes of spacing between footings. The figure illustrates that satisfactory match between results of the numerical model in this study and those by Kumar and Bhattacharya [16] was attained.

\subsection{Single footing on reinforced sand}

Das et al. [20] performed an experimental study to investigate the ultimate bearing capacity of a strip footing with width (B) of $76.2 \mathrm{~mm}$ on geogrid-reinforced sand beds. The
Table $1 \mathrm{~N}_{\gamma}$ values for single footing on unreinforced sand

\begin{tabular}{lllllll}
\hline $\begin{array}{l}\text { Angle of } \\
\text { friction, } \\
\phi\left(^{\circ}\right)\end{array}$ & Present method & $\begin{array}{l}\text { Kumar and } \\
\text { Bhattacharya } \\
{[16]}\end{array}$ & Kumar [7] & $\begin{array}{l}\text { Kumar and } \\
\text { Khatri [6] }\end{array}$ & $\begin{array}{l}\text { Ukritchon } \\
\text { et al. [4] }\end{array}$ & Hijaj et al. [5] \\
\hline 5 & 0.211 & 0.11 & 0.11 & 0.11 & 0.11 & 0.12 \\
10 & 0.532 & 0.42 & 0.43 & 0.4 & 0.41 & 0.43 \\
15 & 1.34 & 1.14 & 1.17 & 1.09 & 1.13 & 1.18 \\
20 & 2.90 & 2.67 & 2.82 & 2.65 & 2.67 & 2.82 \\
25 & 6.30 & 6.09 & 6.46 & 6.02 & 5.95 & 6.43 \\
30 & 14.98 & 13.57 & 14.68 & 13.65 & 13.21 & 14.57 \\
35 & 33.44 & 30.76 & 34.31 & 31.90 & 29.30 & 33.95 \\
40 & 75.75 & 73.24 & 85.1 & 77.88 & 69.9 & 83.33 \\
\hline
\end{tabular}


Fig. 2 Efficiency factor against footing spacing ratio $(\mathrm{S} / \mathrm{B})$ for different angle of internal friction
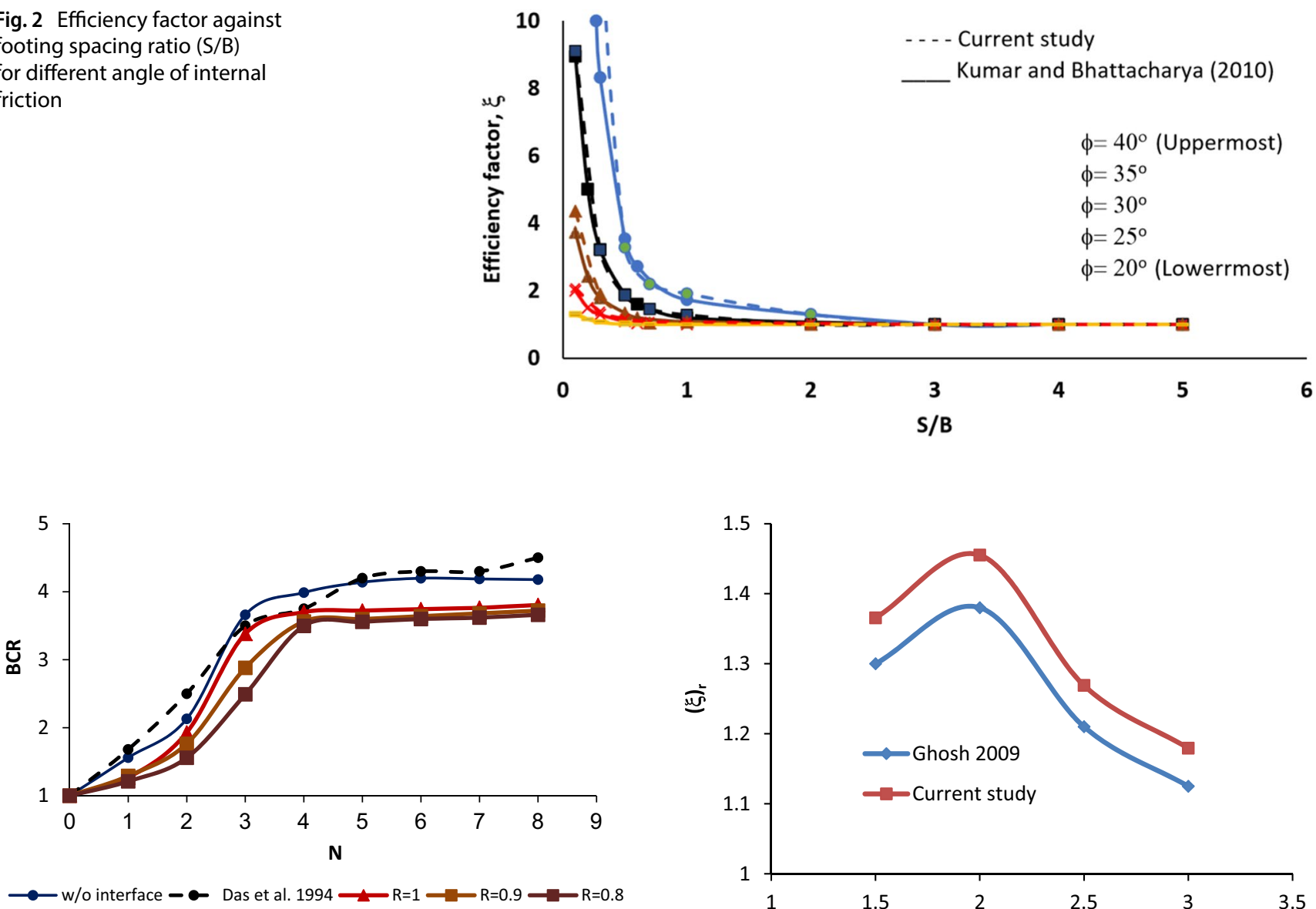

Fig. 3 Effect of number of reinforcement layers and interface elements on BCR in comparison with results of Das et al. [20]

tests were conducted on sand beds that were prepared with a unit weight of $17.14 \mathrm{kN} / \mathrm{m}^{2}$ and had an angle of internal friction of $41^{\circ}$. Geogrid layers were positioned at equal spacing of $h=B / 3$. In addition, the top most layer was placed at $u=B / 3$ beneath the footing. The tensile strength of geogrid reinforcement layers at $2 \%$ strain was $182 \mathrm{kN} / \mathrm{m}^{\prime}$. Eight tests were performed with changing number of reinforcement layers $(\mathrm{N}=1-8)$. The current model is created with the same conditions of Das et al. [20] experiments. Furthermore, the numerical model is employed to study the impact of interface element factor (R) on the numerical results.

A detailed comparison between the results of the developed numerical model without interface elements, Rigid interface $(R=1, R=0.9$ and $R=0.8)$ and experimental data is presented in Fig. 3. The results are presented in terms of bearing capacity ratio (BCR), which is defined as the ratio of the bearing capacity of footing on geogridreinforced sand to that attained on unreinforced soil bed. It is clear that substantial degree of improvement in the value of $B C R$ is observable with increasing number of

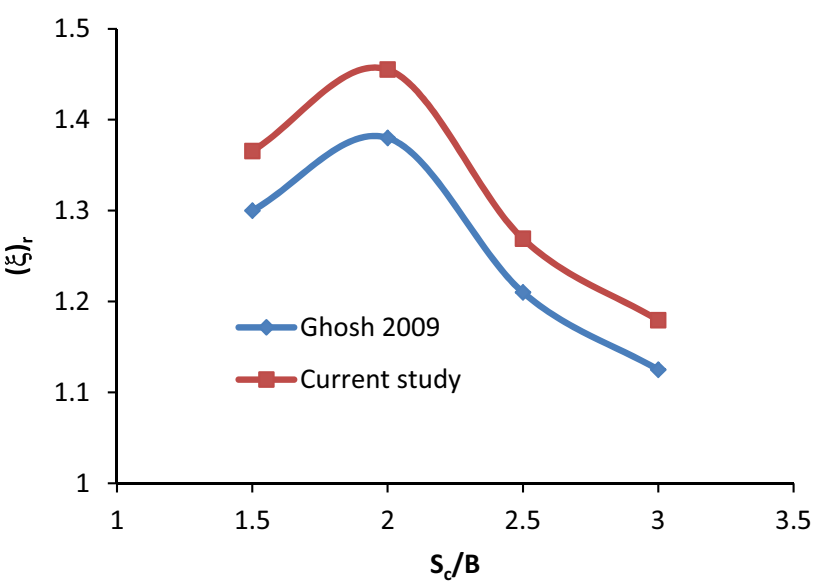

Fig. 4 finite element result for two adjacent strip footings on reinforced sand compared with results reported by Ghosh and Kumar [41]

reinforcement layers up to 3 layers. For reinforced sand beds with 4 layers or more, no significant increase in the bearing capacity was noticed. The results in Fig. 3 shows that the numerical results obtained without consideration of an interface element between reinforcement and surrounding soil are in good agreement with the experimental results. This could be attributed to that the full bond counteracts the missing two mechanisms which are passive resistance membrane resistance. In comparison with test results, the BCR that is determined based on interface element was found to be lower in particular at lower values of $R$.

\subsection{Two strip footing on reinforced sand}

Ghosh and Kumar [41] conducted a series of model test on two adjacent strip footing on reinforced sand. The spacing between footings was examined in order to investigate its influence on the value of bearing capacity. A comparison 
between results of the Finite Element analysis in this study and those obtained experimentally for a system with a single reinforcement layer that was inserted at a depth of $7.5 \mathrm{~cm}$ in a soil with an angle of internal friction of $38.9^{\circ}$ and has a stiffness of $64.5 \mathrm{kN} / \mathrm{m}^{\prime}$ were presented in Fig. 4. It shows the improvement ratio $(\xi)_{\mathrm{r}}$ in bearing capacity against the footing spacing in terms of $\left(s_{C} / B\right)$ where, $(\xi)_{r}$ is the ratio between the bearing capacity of single footing in case of two adjacent footing over reinforced sand to that of single footing and $\mathrm{s}_{\mathrm{c}}$ is center to center footing spacing. The numerical results indicated that similar behavior is obtained with $8 \%$ difference between the results of the numerical and those experimentally attained. Besides, the results indicates that the maximum enhancement in bearing capacity is obtained at $S / B=2$. The numerical model was therefore considered quite capable of simulating the behaviour of footings on unreinforced and reinforced sand beds under different conditions.

\section{Results and discussion}

The finite element model is employed to discover the impact of angle of dilation, internal friction angle and spacing between footings on the performance of strip footing supported by unreinforced and reinforced sand. Besides, the changing in stress and settlement distribution through the different cases is also presented.

\subsection{Effect of angle of dilation $(\psi)$ on value of $\mathrm{N}_{\gamma}$ for a single footing on reinforced and unreinforced sand}

This section presents the results of the study on the effect of dilatancy angle on the ultimate bearing capacity of a single footing on unreinforced and reinforced sand beds. It is well known that during shearing, the positive dilation angle refers to soil expansion and a negative one means that the soil in which the net movement of particles causes contraction [42]. Determination of soil dilatancy generally extracted from existing stress-shear strain relationships. The peak strength of soil is usually associated with the maximum rate of dilation. A great attention has been given for the relationship between the friction angle $(\phi)$ and the dilation angle $(\psi)[38,39,43]$. Disparate understanding concerning the determination of soil dilatancy was recorded due to several affecting factors. Most relationships showed significant effects of stress state, soil density, particles' shape and fine content on soil dilatancy. In addition, the interaction between soil reinforcement and adjacent soil changes the soil dilatancy behavior in which increased volume of soil occurs at failure plane leading to an increase in the dilation angle [44]. Therefore, in this section, a range of angle of dilation is examined to assess its impact on the footing response. Values for the bearing capacity factor $\mathrm{N}_{\gamma}$ are presented in Fig. 5 for different values of $\phi$ due to changing in the dilatancy angle. Although in many studies, the dilation angle of zero has been assumed, the negative dilation angle, as shown in Fig. $5 d$, is acceptable for rather loose sand due to its contractive behaviour under shearing. Figure 5 shows a significant increase in $N_{\gamma}$ with the increase of dilatancy angle for the case of reinforced sand. This could be attributable to increasing in dilatancy due to increasing confining effect of reinforcement. Obviously, the impact of changing of the dilatancy angle in the case of reinforced sand is greater than that observed for unreinforced sand beds. Careful inspections of data presented in Fig. 5 illustrates that higher values of $\mathrm{N}_{\gamma}$ was experienced with increasing number of reinforcement layers. In addition, the relationship between $N_{\gamma}$ and angle of dilation follows a three stages. At the first and third stages, a slight increase in $\mathrm{N}_{\gamma}$ was observed as the dilatancy increased. The third stage seems to initiate at a dilation angle of about $20^{\circ}, 15^{\circ}, 10^{\circ}$, and $5^{\circ}$ for $\phi=40^{\circ}, 35^{\circ}, 30^{\circ}$ and $25^{\circ}$ respectively. Whereas the second stage is apparently a transition zone that was characterized by a significant increase in $\mathrm{N}_{\gamma}$ with increasing angle of dilation but it was dependent on the angle of friction of soil and number of reinforcement layers. The sharp increase in $\mathrm{N}_{\gamma}$ during the transition zone could be attributed to expansion of soil volume upon shearing which led to a reduction in the slack effect [45]. Hence, there would be minimum values for the dilation angle to overcome the slack effect in different reinforced grounds as a function of the packing condition of soil and number of reinforcement layers.

\subsection{Efficiency factor ( $($ ) for multiple strip footing on reinforced sand}

Figure 6 shows the effect of interference between footings on the ultimate bearing capacity which is assessed using an efficiency factor (ל). The efficiency factor $(\zeta)$ is a dimensionless factor and determined as the ratio of ultimate bearing capacity of one footing in a group of strip footings over reinforced sand beds to that observed for a single footing under the same conditions. Of note, the efficiency factor was expressed as a function of the spacing ratio which is often taken as the ratio of clear spacing to the footing width. Figure 6 illustrates the magnitude of (ל) for different values of friction angle with changing spacing ratio $(\mathrm{S} / \mathrm{B})$. It can be noticed that, for all cases, the value of $(\zeta)$ is greater than 1 and increases with the decrease in the value of $(S / B)$. Very limited interaction between adjacent footings was observed for a clear spacing that was twice or more the footing width. The results suggest that 


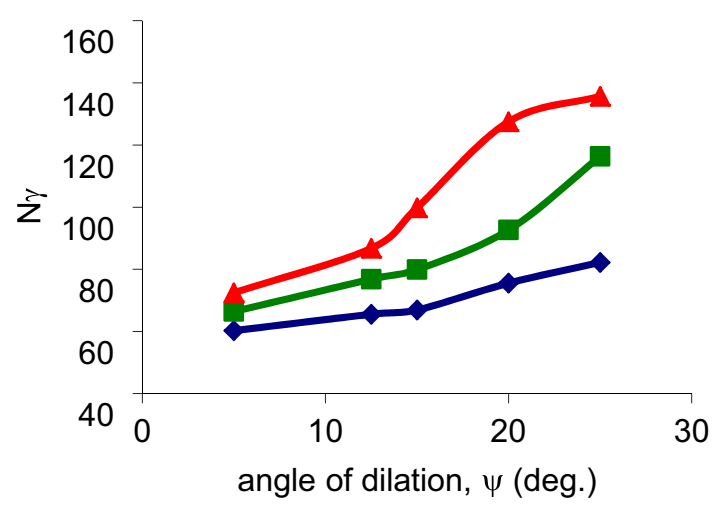

$\longrightarrow$ without reinforcement $\longrightarrow \mathrm{N}=1 \longrightarrow \mathrm{N}=2$

(a) Sand beds with $\phi=40$

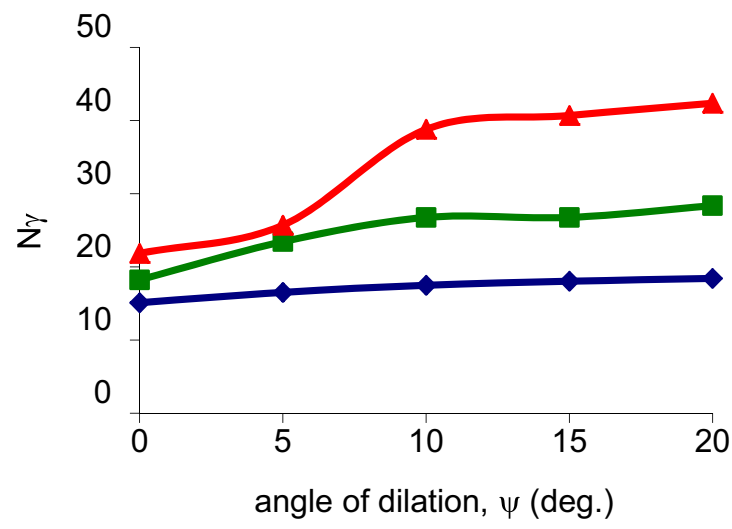

$\longrightarrow$ without reinforcement

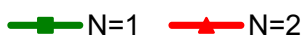

(c) Sand beds with $\phi=30$

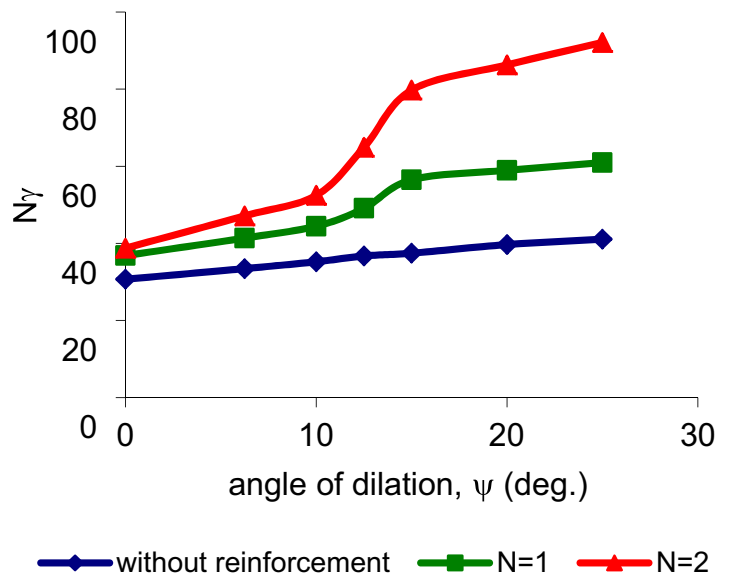

(b) Sand beds with $\phi=35$

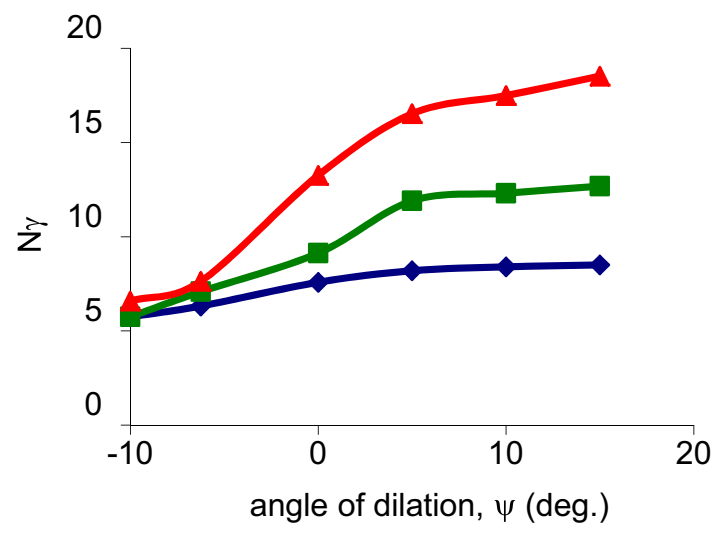

$\longrightarrow$ without reinforcement $\longrightarrow \mathrm{N}=1 \longrightarrow \mathrm{N}=2$

(d) Sand beds with $\phi=25$

Fig. 5 Influence of angle of internal friction and dilation angle on the bearing capacity factor, $\mathrm{N}_{\gamma^{\prime}}$ for a single footing resting on reinforced and unreinforced sand

the angle of friction plays a major role in the interaction between footings and hence the efficiency factor. The efficiency factor always increases with increasing the angle of friction. In case of sand bed with an angle of friction of 40o, the efficiency factor varied between 204 and 1 for the case of $\mathrm{N}=1$ and between 232 and 1 for sand beds with two layers of reinforcement. On the other hand, for other values of angle of frictions $(\phi)$, the values of the efficiency factor were found to range between 1 and 6.8 for case of $\mathrm{N}=1$ and varies between 1 and 18 for case of $\mathrm{N}=2$. It can be noticed that the increasing number of reinforcement layers did not help in loose sands whereas it worked well in medium to dense sand with $\phi>30^{\circ}$. The same results are illustrated in other form in Fig. 7 whereas the efficiency factor is related to the angel of internal friction and the same trend can be observed. It is clear that the efficiency factor increases with the reduction in the spacing between multiple footings, number of reinforcement layers and friction angle.

Figure 8 illustrates an example of shear stress distribution of unreinforced and reinforced sand beds. It can be noted that the shear stress $t_{x y}$ along the vertical planes at boundary condition (axis of symmetry) becomes to zero.

The distribution of normal stress $\left(\sigma_{y}\right)$ underneath closely spaced strip footings for both reinforced and unreinforced soil beds are presented in Figs. 9 and 10 . It can be noticed that the reinforcement layers play an important role in redistribution of the stress. At the same level of applied loading, Fig. 9 shows a comparison between unreinforced and reinforced sand $(N=1,2)$ in terms of $\sigma_{y}$ for the case of $\phi=30^{\circ}$ and $S / B=0.3$. All of three cases are loaded by the ultimate bearing pressure 


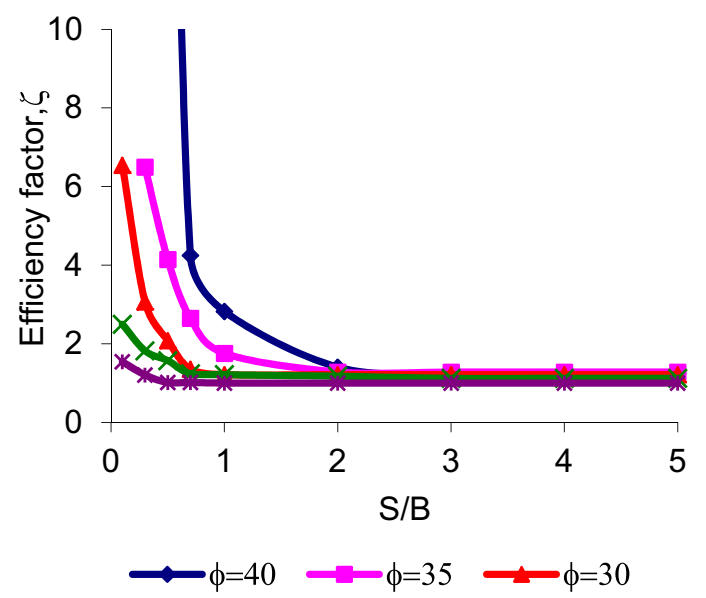

(a) One layer reinforcement $(\mathrm{N}=1)$

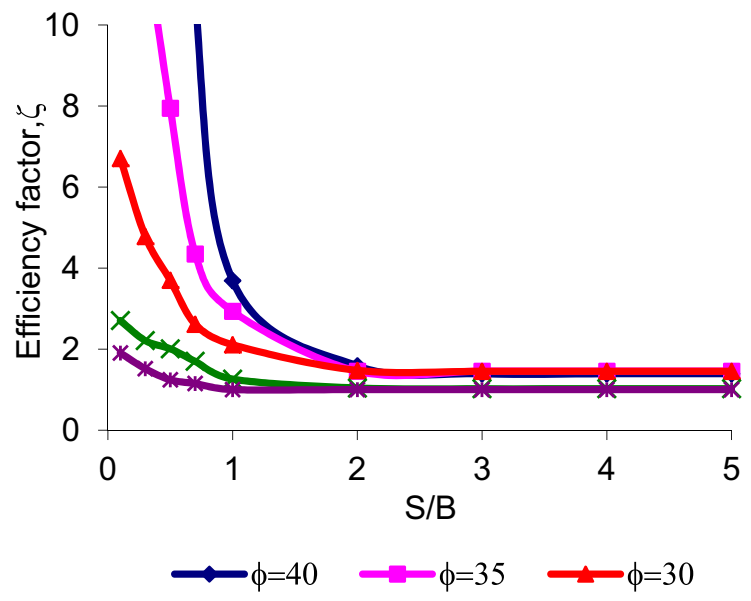

(b) Two layers reinforcement $(\mathrm{N}=2)$

Fig. 6 Efficiency factor for reinforced sand with variation of angle of internal friction and footing spacing (S/B)

that was determined on unreinforced sand bed. As shown in, the maximum $\sigma_{y}$ for reinforced soil reduced by $39.7 \%$ and $42.6 \%$ for the cases of sand beds with one and two layers of reinforcement respectively in comparison with those on unreinforced sand beds. This could be attributed to the effect of reinforcement on lateral spreading of induced stress than that occurs on unreinforced soil i.e., the volume of soil which withstands the footing load is bigger due to the apparent cohesion caused by reinforcement. In other words, for unreinforced sand, the applied footing pressure distributes over a relatively small area which is dependent on the angle of friction and depth from the bottom of the footing. On the other hand, in the case of reinforced sand, the load transfer mechanism is greatly affected by the existence of reinforcing layers. The generation of shear stresses on both sides of reinforcement layers results in the redistribution of stresses over larger zone. In addition, insertion of the reinforcement layers increase the confining stress around loaded area in comparison with that in unreinforced sand at the same load level and depth.

Figure 11 shows the distribution of horizontal soil movement Ux for the same cases at the same conditions in order to highlight the confining effect induced by the reinforcement. It shows clearly that the horizontal movement under strip footing highly influenced by soil reinforcement. Whereas, the horizontal displacement, in comparison with that on unreinforced sand bed, reduced by $57.6 \%$ and $61.8 \%$ on reinforced sand beds with one and two layers of reinforcements respectively. It can be concluded that the presence of reinforcement layers increases the interaction between closely spaced footings and causes remarkable confinement which in turn, enhanced substantially the soil resistance to applied bearing pressure.

On the other hand, Fig. 10 shows the distribution of $\sigma_{y u}$ inside the soil mass at ultimate bearing capacity of each case. It can be observed that the ratios between the maximum normal stress on reinforced sand bed and that for unreinforced one are found to be 1.57 and 2.74 for one and two layers of reinforcement respectively. In addition, due to the reinforcement materials, the interlocking between soil particles increases leading to a deeper stress distribution in the case of reinforced beds than that observed on unreinforced sand bed.

\subsection{Equivalent cohesion for reinforced sand}

In this section, an equivalent approach is presented to estimate the ultimate bearing capacity of strip footing on reinforced sand so as to avoid simulation of complex interactions between soil and reinforcement layers. The improvement in ultimate bearing capacity by reinforcement is achieved by assuming an apparent cohesion. Whereas, the reinforcement depth (d) is replaced by an equivalent layer with homogenous properties. The strength characteristics are defined by both of friction angle $(\phi)$ and cohesion (c). The cohesion parameter has been termed as apparent cohesion by some researchers to account for the additional confinement caused by inclusion of reinforcement layers [46]. Therefore, the shear strength, due to reinforcement, for granular material can be expressed by:

$\tau_{\mathrm{r}}=\mathrm{c}_{\mathrm{r}}+\sigma^{\prime} \tan \phi^{\prime}$ 


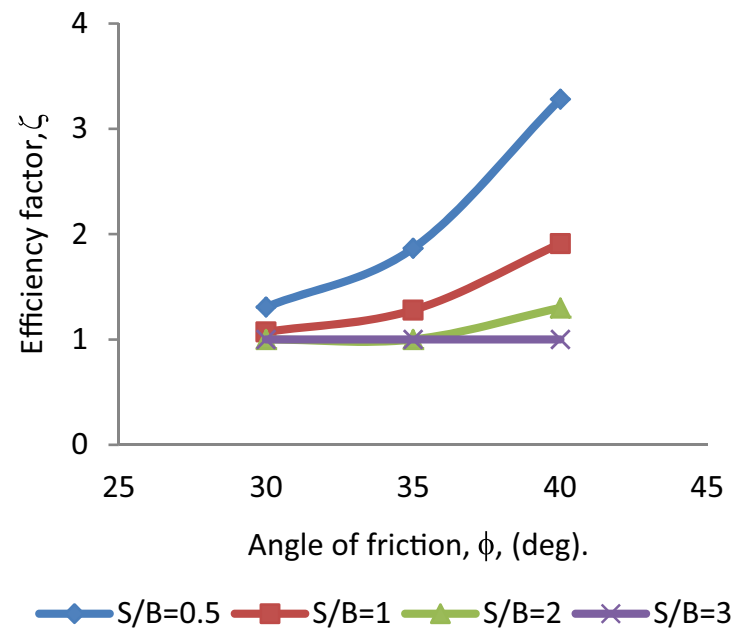

(a) Unreinforced sand

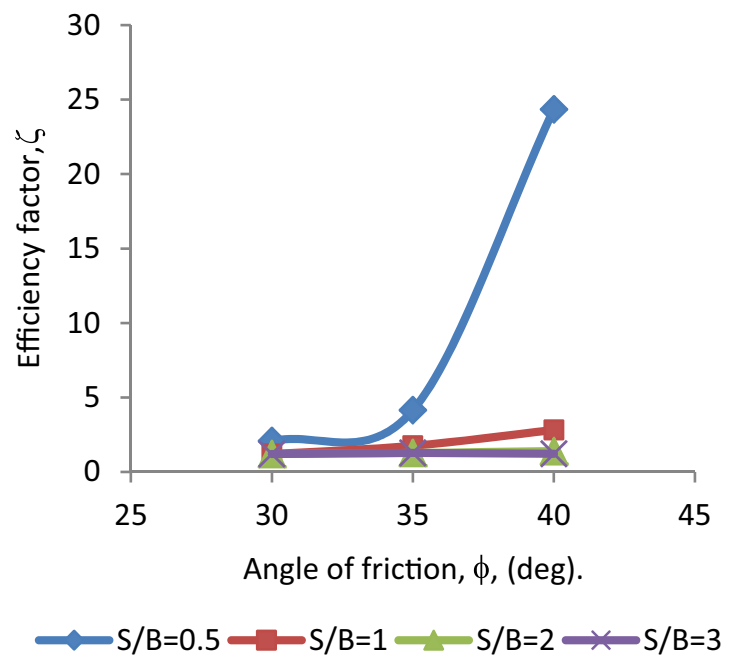

(b) One layer reinforcement $(\mathrm{N}=1)$

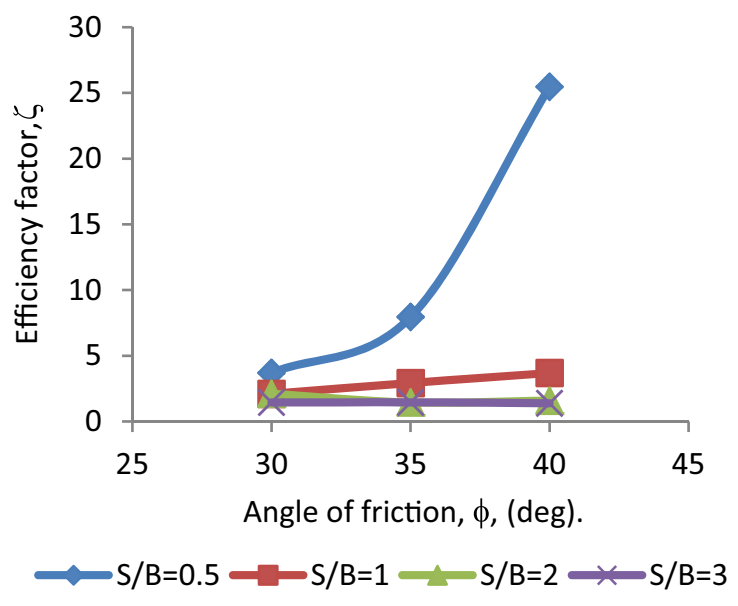

(c) Two layers reinforcement $(\mathrm{N}=1)$

Fig. 7 Efficiency factor for unreinforced and reinforced versus angle of internal friction

where $r$ stands for reinforced composition, $\tau_{r}=$ shear strength; $c_{r}=$ apparent cohesion, $\sigma^{\prime}=$ effective normal stress. Several studies were performed to investigate the characteristics of shear strength of reinforced soil by conducting shear box and triaxial tests $[47,48]$.

In this numerical analysis, an apparent cohesion was added alongside with the internal friction angle of sand to simulate the benefits of reinforcement in attempt to simplify modelling and computational cost of interactions between reinforcement layers and adjacent soils.
Relies on the obtained results of Das et al. [20] which were discussed in Sect. 4.2, the applicability of equivalent cohesion approach is evaluated. Their experimental study is simulated by performing the present numerical model without reinforcement to predict the equivalent cohesion which represents the rise in ultimate bearing capacity caused by reinforcement. Table 2 shows the values of equivalent cohesion $\left(c_{\mathrm{re}}\right)$ through changing of the number of reinforcement layers for reinforced sand $\left(\phi=41^{\circ}, \mathrm{u}=\mathrm{h}=25.4 \mathrm{~mm}\right)$. Figure 12 shows a good agreement between results predicted by 
Fig. 8 shear stress distribution for group of strip footing

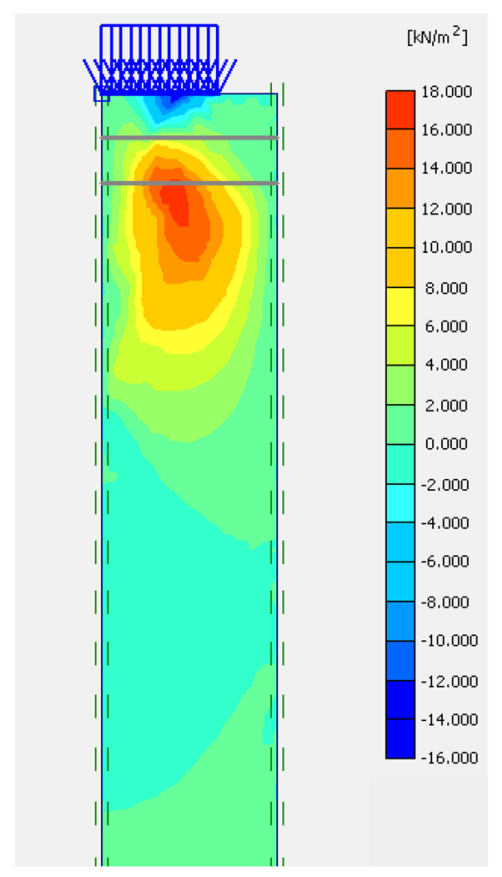

(a) shear stress at failure stage for unreinforced sand

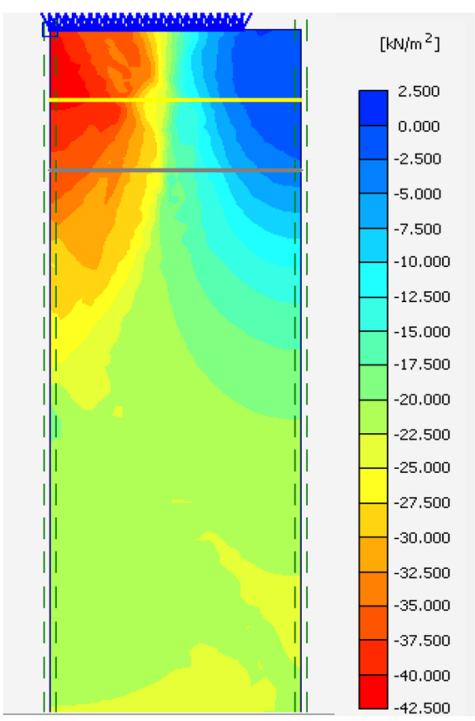

(b) Reinforced sand, $\mathrm{N}=1$

$$
\sigma_{\text {ymax }}=41 \mathrm{kN} / \mathrm{m}^{2}
$$

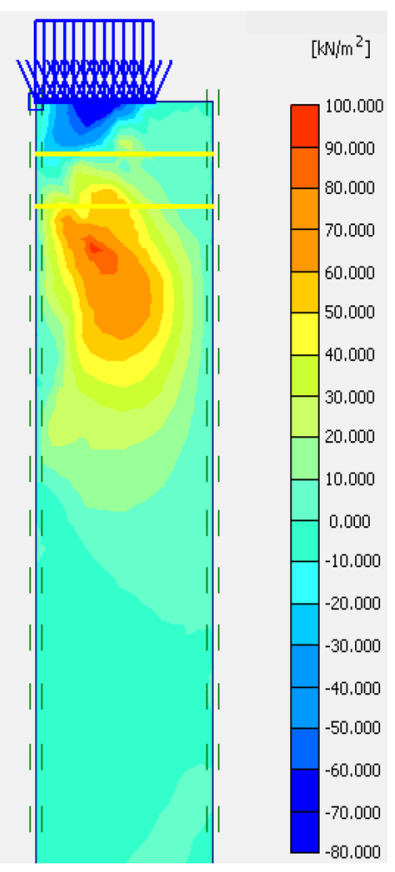

(b) shear stress at failure stage for reinforced sand

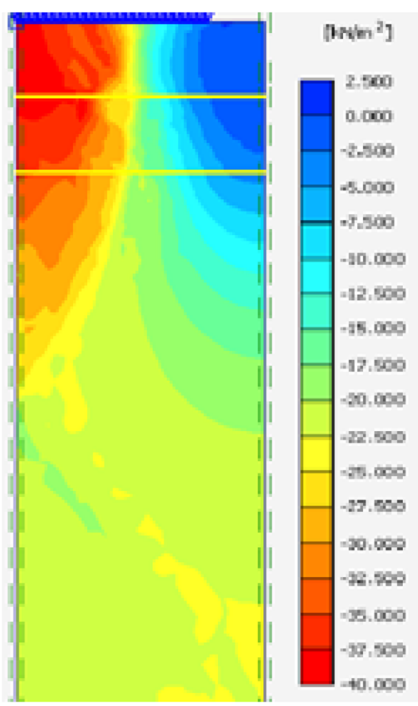

(c) Reinforced sand, $\mathrm{N}=1$

$$
\sigma_{\text {ymax }}=39 \mathrm{kN} / \mathrm{m}^{2}
$$

Fig. 9 Normal stress distribution for reinforced and unreinforced sand at the same load level for case of $\phi=30^{\circ}, S / B=0.3$

and equivalent approach. It therefore suggested that the equivalence approach seems promising and might shorten the computational time significantly. Further research is underway to assess it fully using experiment data. 


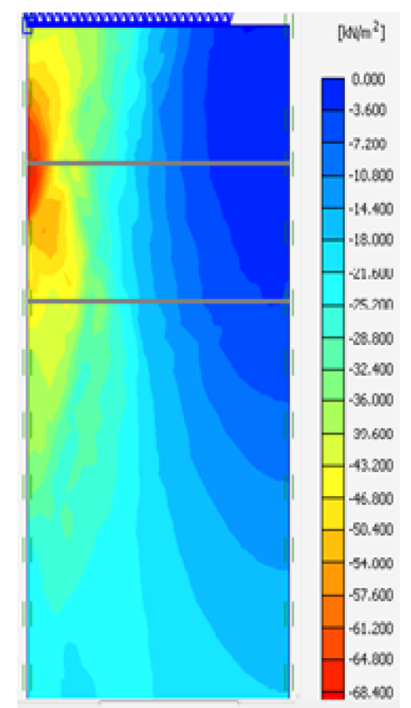

(a) Unreinforced sand $\sigma_{\mathrm{yu}}=68 \mathrm{kN} / \mathrm{m}^{2}$

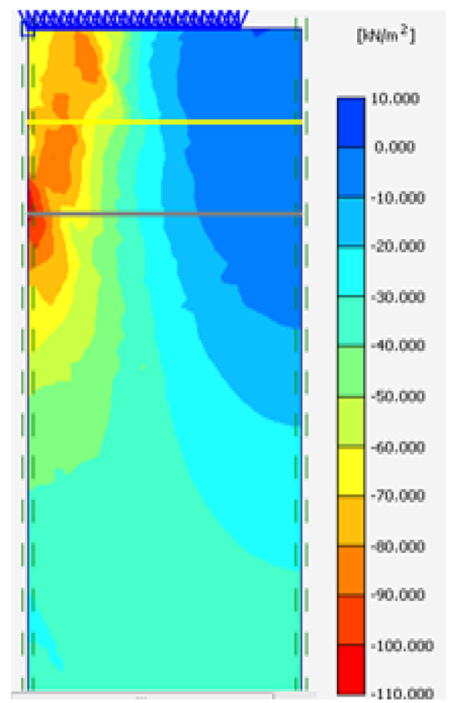

(b) Reinforced sand, $\mathrm{N}=1$ $\sigma_{\mathrm{yu}}=107.17 \mathrm{kN} / \mathrm{m}^{2}$

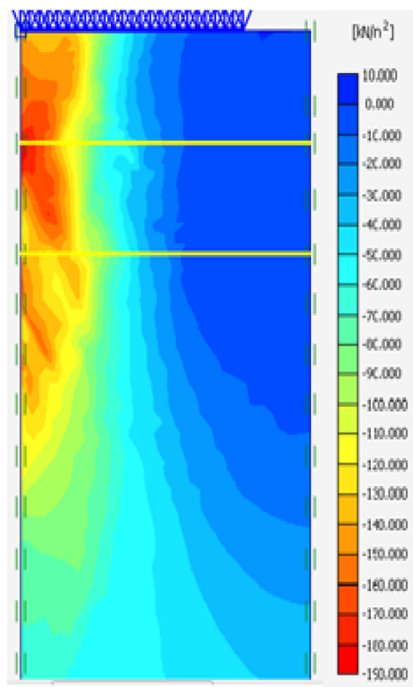

(c) Reinforced sand, $\mathrm{N}=1$ $\sigma_{\mathrm{yu}}=186.41 \mathrm{kN} / \mathrm{m}^{2}$

Fig. 10 Normal stress distribution for reinforced and unreinforced sand at ultimate bearing capacity for case of $\phi=30^{\circ}, \mathrm{S} / \mathrm{B}=0.3$

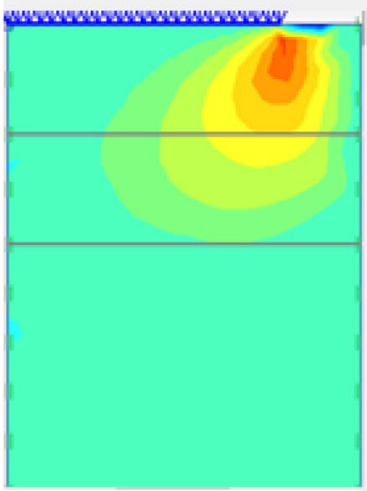

(a) Unreinforced sand $\mathrm{U}_{\mathrm{xymax}}=0.144 \mathrm{~mm}$

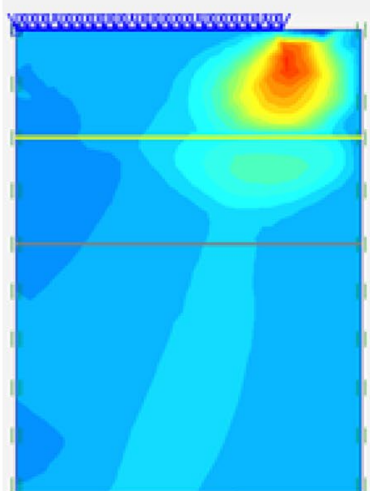

(b) Reinforced sand, $\mathrm{N}=1$ $\mathrm{U}_{\mathrm{xymax}}=0.061 \mathrm{~mm}$

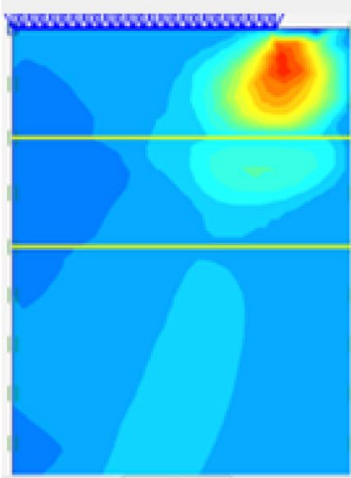

(c) Reinforced sand, $\mathrm{N}=1$ $\mathrm{U}_{\mathrm{xymax}}=0.055 \mathrm{~mm}$

Fig. 11 Horizontal displacement (Ux) distribution for reinforced and unreinforced sand at the same load level for case of $\phi=30^{\circ}, S / B=0.3$

Table 2 shows the values of equivalent cohesion $\left(c_{r e}\right)$ through changing of the number of reinforcement layers

\begin{tabular}{lll}
\hline $\begin{array}{l}\text { Reinforcement layers } \\
(\mathrm{N})\end{array}$ & $\begin{array}{l}\text { Reinforcement depth } \\
(\mathrm{d})(\mathrm{mm})\end{array}$ & $\begin{array}{l}\text { Equivalent cohe- } \\
\text { sion }\left(\mathrm{C}_{\mathrm{e}}\right)\left(\mathrm{kN} / \mathrm{m}^{2}\right)\end{array}$ \\
\hline 1 & 25.4 & 8 \\
2 & 50.8 & 8 \\
3 & 76.2 & 26 \\
4 & 101.6 & 26 \\
5 & 127 & 18 \\
\hline
\end{tabular}

\section{Conclusions}

A comprehensive numerical study was conducted to assess the effects of interference and interactions between closely spaced strip footings on unreinforced and reinforced sand beds. The developed numerical model was verified using data from multiple studies on a single footing on unreinforced and reinforced sand beds. An efficiency factor was introduced and utilized 


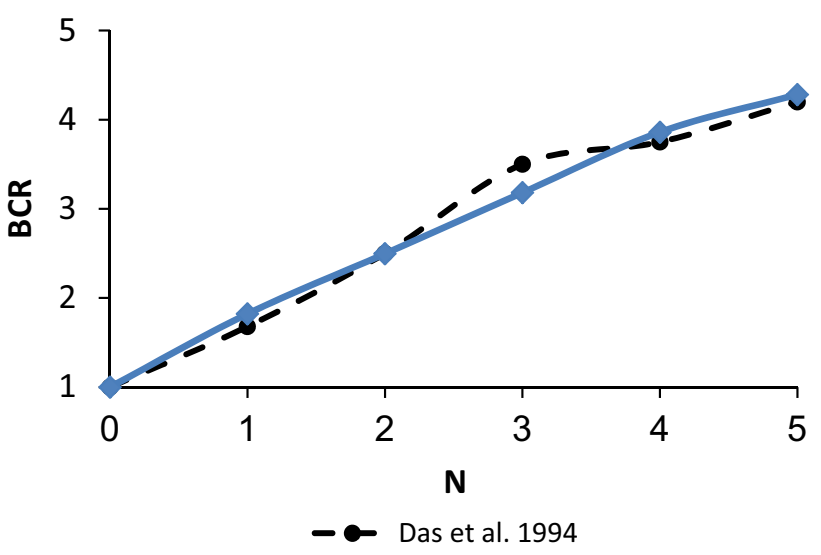

Fig. 12 Equivalent approach compared by Das et al. [20]

to assess the degree of improvement on bearing capacity. A number of conclusions could be drawn from the numerical study;

1. The verification exercise illustrated that the developed numerical model is capable of modelling the behavior of footings on unreinforced and reinforced sand beds.

2. The numerical results for a single footing on unreinforced and reinforced sand beds illustrated clearly that the bearing capacity factor $\mathrm{N}_{\gamma}$ is dependent on the angle of friction, angle of dilation and number of reinforcement layers.

3. The efficiency factor for multiple strip footings on reinforced sand beds improves markedly with decreasing the spacing between adjacent footings. The interaction between adjacent footings seems minor when the value of $S / B$ is greater than 2 .

4. Normal stress underneath multiple strip footings is reduced by around $40 \%$ with the inclusion of layers of reinforcement in comparison with the unreinforced sand bed. In addition, stresses are distributed over larger area in case of reinforced sand beds.

5. An alternative approach is assessed that relies on the use of apparent cohesion. The use of apparent cohesion seems promising but further experimentations are required so as to provide concrete conclusions.

\section{Compliance with ethical standards}

Conflict of interest On behalf of all authors, the corresponding author states that there is no conflict of interest.

\section{References}

1. Terzaghi K (1943) Theoretical soil mechanics. Wiley, New York

2. Meyerhof G (1965) Shallow foundations. J Soil Mech Found Div ASCE 91(SM2):21-31

3. Manoharan N, Dasgupta SP (1995) Bearing capacity of surface footings by finite elements. Comput Struct 54(4):563-586

4. Ukritchon B, Whittle AW, Klangvijit C (2003) Calculation of bearing capacity factor $N_{\gamma}$ using numerical limit analysis. J Geotech Geoenviron Eng ASCE 129(7):468-474

5. Hjiaj M, Lyamin AV, Sloan SW (2005) Numerical limit analysis solutions for the bearing capacity factor $N_{\gamma}$. Int J Solids Struct 42(5):1681-1704

6. Kumar J, Khatri VN (2008) Effect of footing width on $N_{\gamma}$. Can Geotech Eng 45:1673-1684

7. Kumar J (2009) The variation of $N_{\gamma}$ with footing roughness using the method of characteristics. Int J Numer Anal Methods Geomech 33(2):275-284

8. Benmebarek S, Remadna MS, Benmebarek N, Belounar L (2012) Numerical evaluation of the bearing capacity factor $N_{\gamma}{ }^{\prime}$-of ring footings. Comput Geotech 44:132-138

9. Das BM, Larbi-Cherif S (1983) Bearing capacity of two closelyspaced shallow foundations on sand. Soils Found 23(1):1-7

10. Kumar J, Ghosh P (2007) Ultimate bearing capacity of two interfering rough strip footings. Int J Geomech ASCE 7(1):53-62

11. Kumar J, Kouzer KM (2008) Bearing capacity of two interfering footings. Int J Numer Anal Methods Geomech 32:251-264

12. Kumar J, Bhoi MK (2008) Interference of two closely spaced strip footings on sand using model tests. J Geotech Geoenviron Eng ASCE 134(4):595-604

13. Graham J, Raymond GP, Suppiah A (1984) Bearing capacity of three closely-spaced footings on sand. Géotechnique 34(2):173-182

14. Kouzer KM, Kumar J (2008) Ultimate bearing capacity of equally spaced multiple strip footings on cohesionless soils without surcharge. Int J Numer Anal Methods Geomech 32:1417-1426

15. Lee J, Eun J (2009) Estimation of bearing capacity for multiple footing in sand. Comput Geotech 37:1000-1008

16. Kumar J, Bhattacharya $P$ (2010) Bearing capacity of interfering multiple strip footings by using lower bound finite elements limit analysis. Comput Geotech 36:731-736

17. Binquet J, Lee KL (1975) Bearing capacity tests on reinforced earth slabs. J Geotech Eng Div 101(GT12):1241-1255

18. Binquet J, Lee KL (1975) Bearing capacity tests on reinforced earth slabs. J Geotech Eng Div 101(GT12):1257-1276

19. Huang CC, Tatsuoka F (1990) Bearing capacity reinforced horizontal sandy ground. Geotext Geomembr 9:51-82

20. Das BM, Shin EC, Omar MT (1994) The bearing capacity of surface strip foundations on geogrid reinforced sand and clay-a comparative study. Geotech Geol Eng 12(1):1-14

21. Adams MT, Collin JG (1997) Large model spread footing load tests on geosynthetic reinforced soil foundations. J Geotech Geoenviron Eng 123(1):66-72

22. Basudhar PK, Saha S, Deb L (2007) Circular footings resting on geotextile reinforced sand bed. Geotext Geomembr 25(6):377-384

23. Chen Q, Abu-farsakh M, Sharma R, Zhang X (2004) Laboratory investigation of behavior of foundations on geosynthetic-reinforced clayey soil. Transp Res Rec J Transp Res Board 2004:28-38

24. Chen Q, Abu-Farsakh M, Sharma R (2009) Experimental and analytical studies of reinforced crushed limestone. Geotext Geomembr 27(5):357-367 
25. Sharma R, Chen Q, Abu-Farsakh M, Yoon S (2009) Analytical modeling of reinforced soil foundation. Geotext Geomembr 27(1):63-72

26. Lavasan AA, Ghazavi M (2012) Behavior of closely spaced square and circular footings on reinforced sand. Soils Found 52(1):160167. https://doi.org/10.1016/j.sandf.2012.01.006

27. Zidan AF (2012) Numerical study of behaviour of circular footing on geogrid reinforced sand under static and dynamic loading. Geotech Geol Eng 30(2):499-510

28. Abu-Farsakh $M$, Chen $Q$, Sharma R, Zhang X (2008) Large-scale model footing tests on geogrid reinforced marginal embankment soil. Geotech Test J ASTM 31(5):413-423

29. Abu-Farsakh M, Chen Q, Sharma R (2013) An experimental evaluation of the behavior of footings on geosynthetic-reinforced sand. Soils Found 53(2):335-348

30. Demir A, Laman M, Yildiz A, Ornek M (2013) Large scale field tests on geogrid-reinforced granular fill under lain by clay soil. Geotext Geomembr 38:1-15

31. Chakraborty M, Kumar J (2014) Bearing capacity of circular foundations reinforced with geogrid sheets. Soils Found 54(4):820-832

32. Kumar A, Saran S (2003) Closely spaced footings on geogridreinforced sand. J Geotech Geoenviron Eng ASCE 129(7):660

33. Ghazavi M, Lavasan AA (2008) Interference effect of shallow foundations constructed on sand reinforced with geosynthetics. Geotext Geomembr 26(5):404-415

34. Eltohamy A, Zidan AF (2013) Performance of interfering strip footings resting on reinforced sand under uniform and nonuniform load-experimental and numerical study. J Am Sci 9(1):421-430

35. Roy SS, Dep K (2019) Influence of footing interference on bearing capacity improvement for geogrid-reinforced sand bed underlain by soft clay. In: Eighth international conference on case histories in geotechnical engineering geo-congress, Philadelphia, Pennsylvania, pp 24-27

36. Bringkgreve RBJ, Vermeer PA (1998) PLAXIS-finite element code for soil and rock analyses. Version 8.2 Plaxis BV, The Netherlands
37. El Sawwaf M (2007) Behavior of strip footing on geogrid reinforced sand over a soft clay slope. Geotext Geomembr 25(1):50-60

38. Rowe PW (1962) The stress-dilatancy relation for static equilibrium of an assembly of particles in contact. Proc R Sot 269A:5OG-527

39. Rowe PW (1969) The relation between the shear strength of sands in triaxial compression, plane strain and direct shear. Geotechnique 19(1):75-86

40. Been K, Jefferies MG, Hachey J (1991) The critical state of sand. Geotechnique 41(3):365-381

41. Ghosh P, Kumar P (2009) Interference effect of two nearby strip footings on reinforced sand. Contemp Eng Sci 2(12):577-592

42. Budhu M (2000) Soil mechanics and foundations. Wiley, New York

43. De Josselin De Jong G (1976) Rowe's stress-dilatancy relation based on friction. Geotechnique 26(3):527-534

44. Bathurst RJ, Simac MR (1993) Laboratory testing of modular unit-geogrid facing connections. In: Cheng SCJ (ed) STP 1190 geosynthetic soil reinforcement testing procedures. American Society for Testing and Materials (Special Technical Publication)

45. Abu-Farsakh M, Chen Q, Sharma R (2013) An experimental evaluation of the behavior of footings on geosynthetic-reinforced sand. Soil Found 53(2):335-348

46. Shukla SK, Shivakugan N, Singh AK (2010) Analytical model for fiber-reinforced granular soil under high confining stress. J Mater Civ Eng ASCE 22(9):935-942

47. Infante DJU, Martinez GMA, Arrua PA, Eberhardt M (2016) Shear strength behavior of different geosynthetic reinforced soil structure from direct shear test. Int J Geosynth Ground Eng 2:17

48. Maji VB, Sowmiyaa VS, Robinson RG (2016) A simple analysis of reinforced soil using equivalent approach. Int J Geosynth Ground Eng 2:16

Publisher's Note Springer Nature remains neutral with regard to jurisdictional claims in published maps and institutional affiliations. 